\title{
Determinants of Patient Delay in Seeking Diagnosis and Treatment among Moroccan Women with Cervical Cancer
}

\author{
Fatima Ouasmani, ${ }^{1}$ Zaki Hanchi, ${ }^{2}$ Bouchra Haddou Rahou, \\ Rachid Bekkali, ${ }^{3}$ Samir Ahid, ${ }^{4}$ and Abdelhalem Mesfioui ${ }^{1}$ \\ ${ }^{1}$ Laboratory of Genetic, Neuroendocrinology and Biotechnology, Faculty of Sciences, Ibn Tofail University, Kenitra, Morocco \\ ${ }^{2}$ National Institute of Oncology, Rabat, Morocco \\ ${ }^{3}$ Lalla Salma Foundation-Prevention and Treatment of Cancers, Rabat, Morocco \\ ${ }^{4}$ Laboratory of Epidemiology and Clinical Research, Medical and Pharmacy School, Mohammed V University, Rabat, Morocco
}

Correspondence should be addressed to Fatima Ouasmani; fatouasmani@hotmail.com

Received 11 August 2016; Accepted 12 October 2016

Academic Editor: Peter E. Schwartz

Copyright (C) 2016 Fatima Ouasmani et al. This is an open access article distributed under the Creative Commons Attribution License, which permits unrestricted use, distribution, and reproduction in any medium, provided the original work is properly cited.

\begin{abstract}
Introduction. This study sought to investigate potential determinants of patient delay among Moroccan women with cervical cancer. Methods. A cross-sectional study was conducted from June 2014 to June 2015 at the National Institute of Oncology in Rabat. Data were collected using questionnaire among patients with cervical cancer locally advanced or metastatic (stages IIA-IVB). Medical records were abstracted to complete clinical information. An interval longer than 90 days between discovery of initial symptoms and presentation to a provider was defined as a patient delay. Results. Four hundred and one patients with cervical cancer enrolled in this study. The mean age was 52.4 years $(S D=11.5) .53 .6 \%$ were illiterate. Abnormal vaginal bleeding was identified for $65.8 \%$ of patients. $60.1 \%$ were diagnosed at stages IIA-IIB. $55.4 \%$ were found having patient delay. The regression analyses showed the association between literacy $(p<0.001)$, distance of the place of the first consultation $(p=0.031)$, abnormal vaginal bleeding as an earlier symptom $(p<0.001)$, stage at diagnosis $(p<0.03)$, knowledge of symptoms $(p<0.001)$, knowledge of causes $(p=$ $0.008)$, and practice of gynecological exam during the last three years $(p=0.018)$ and the patient delay. Conclusion. Educational messages should aim at increasing awareness of cervical cancer, assisting women in symptom recognition, and encouraging earlier presentation.
\end{abstract}

\section{Introduction}

Cervical cancer with an estimated 528,000 new cases is the fourth most common cancer in women worldwide. The large majority, around $85 \%$ of the global burden of the disease, occurs in the less developed regions [1]. In developed countries, the incidence of cervical cancer has decreased dramatically since the introduction of cervical screening programs. However, in developing countries the disease incidence remains high. Cervical cancer is the most curable form of any human cancer if detected early at the precancerous stage $[2,3]$ but the challenge is that $80 \%$ of women in the developing countries seek medical care after they have developed signs and symptoms [4]. One of the most important prognostic factors for cervical cancer is how early the disease is when detected and how far it has spread. Delay in diagnosis and treatment continues to be the greatest hurdle to be overcome in the fight to cure cancer $[5,6]$

In Morocco, cervical cancer is increasingly becoming a major public health concern. It is considered the second leading cancer in women and causes high morbidity and mortality. The majority of cases present to hospitals at late stages when treatment is less feasible [7]. Nearly 2258 cases of cervical cancer are diagnosed annually and 1076 die, with an age-standardized incidence rate of 14.3 per 100,000 per annum, and it accounts for $12.8 \%$ of total female cancer [8]. Though the incidence rate of cervical cancer is low in Morocco, the mortality ratio is high which indicates that most of the cancer cases are diagnosed in advanced stages, $43.7 \%$ in stage II and $38.1 \%$ in stages III and IV [9]. 
Advanced cervical cancer is one of the major causes of cancer related mortality in women specially in low- and mediumincome countries mostly due to poor access to appropriate management $[3,6]$. Factors such as unavailability to routine screening, inadequate follow-up of abnormal pap smears, and possibly low awareness of women's population regarding the course of the disease could explain the higher mortality of cervical cancer [10].

Recently, the concept of delayed diagnosis has become an important issue in the cancer prevention and treatment. The concept is categorized in four components including patient delay, health care provider delay, referral delay, and system delay, though all of the mentioned delays have important role in the prevention, diagnosis, and management of the disease but it seems that in developing countries patient delay has more crucial role $[11,12]$.

Delays may occur at different stages of the cancer diagnostic journey and have been commonly defined as being either patient focused or health care provider focused $[5,12]$.

However, to our knowledge, little information is available concerning knowledge and practice as determinants of patient delay in seeking diagnosis and treatment among women with cervical cancer in Morocco. The present study was, therefore, attempted to address some extensive information directly from patients in a hospital based setting and sought to identify potential determinants of patient delay in Moroccan women with cervical cancer.

\section{Methods}

We conducted a cross-sectional study at the National Institute of Oncology Sidi Mohammed Ben Abdellah in Rabat, specifically in gynecological and breast pole. This institute, which is part of the Ibn Sina University Hospital of Rabat, is dedicated exclusively to fighting cancer. It is the referral hospital for cancer care where most of the cases are diagnosed and treated. The protocol of this study was approved by Ethics Committee for Biomedical Research, Faculty of Medicine and Pharmacy of Rabat, Mohammed V University. After obtaining written informed consent from each patient, the data was collected between June 2014 and June 2015 using a face to face structured questionnaire. This tool was pretested and modified before final data collection was done. Data on clinical variables was extracted from hospital record of the patients under study. All interviews were conducted by the searcher.

Moroccan women who had already started their treatment for cervical cancer, who have a hospital record in the National Institute of Oncology, who attend the hospital for processing or checking during the study period, and who have signed a letter of informed consent to participate in the study were included in the study. A consecutive series was carried out for eligible patients with cervical cancer locally advanced or metastatic (IIA-IVB) (The International Federation of Gynecology and Obstetrics (FIGO), Committee on Gynecologic Oncology) [13]. Patients diagnosed with cervical cancer but who have not yet started treatment and patients with psychiatric disorders were excluded from the study.
The sample size was calculated from a proportion of $54.5 \%$ cervical cancer patients who delayed seeking health care [9] with $5 \%$ of precision and $95 \%$ for confidence interval. The minimum sample size $n=373$ was obtained using the formula developed by Schwartz [14]. All cervical cancer patients in one year of the study that meet the inclusion criteria were involved and were able to reach a total of 401 .

The variables included in data analysis were age, marital status, education level, education status of husband, residence, occupation, socioeconomic status, health insurance, remoteness of the first consultation place, medical history, type of earlier symptoms, personal history of cancer, family history of cancer, histopathology, clinical stage of tumor, knowledge of cervical cancer symptoms, causes, screening program, transmission mode, and treatment, and practice of pap smear, gynecological examination, and screening program.

Patient delay refers to a prolonged interval between discovery of initial symptoms and presentation to a provider who can be a general practitioner, a gynecologist, a midwife, or a nurse and is typically defined as greater than 90 days (three months) [15].

The patients were divided into two groups, those who sought medical care within 90 days or less and those who sought medical care more than 90 days after the first symptom recognition. Patients were excluded if this time interval could not be confirmed.

Data analysis was performed in computer using the software Statistical Package for Social Sciences (SPSS) version 13. Chi Square test and $p$ value at $95 \%$ confidence level were used to predict the association. Multivariate binary logistic regression analysis was performed to measure the association between study variables and magnitude of patient delay. Adjusted odds ratio (OR) with its corresponding 95\% confidence interval (CI) was calculated. Significance was when $p<0.05$.

\section{Results}

The distribution of the patients according sociodemographic and clinical data characteristics is presented in Table 1. In total of four hundred and one patients enrolled in the study, $53.4 \%$ were older than 50 years. The mean age was 52.4 years $(\mathrm{SD}=11.48)$ with the range from 28 to 83 years. $53.6 \%$ were illiterate and $63.3 \%$ were married. More than half of patients were urban inhabitants $(68.6 \%)$. In $78.6 \%$ of the patients, the first consultation place from the residence was at a distance of less than $3 \mathrm{~km}$; of all patients $81 \%$ were poor and $80.8 \%$ were unemployed. The majority of patients had a social security (97.5\%).

As an earlier symptom, abnormal vaginal bleeding was identified for $65.8 \%$ of patients. Greater proportion, $87 \%$, of the patients had squamous cell tumor type and $60.1 \%$ of total patients were diagnosed at stages IIA-IIB. Only $10.2 \%$ of patients had a family history of cancer.

Regarding knowledge and practice data, the results showed that $48.9 \%$ of all patients have never heard about cervical cancer and $60.3 \%$ did not know the abnormal vaginal 
TABLE 1: Sociodemographic and clinical characteristics of the study population $(n=401)$.

\begin{tabular}{|c|c|c|}
\hline Characteristics & $n$ & $\%$ \\
\hline \multicolumn{3}{|l|}{ Age (year) } \\
\hline$\leq 50$ & 187 & 46.6 \\
\hline$>50$ & 214 & 53.4 \\
\hline \multicolumn{3}{|l|}{ Marital status } \\
\hline Married & 254 & 63.3 \\
\hline Single & 9 & 2.3 \\
\hline Divorced & 56 & 14 \\
\hline Widow & 82 & 20.4 \\
\hline \multicolumn{3}{|l|}{ Education status } \\
\hline Illiterate & 215 & 53.6 \\
\hline Primary level & 93 & 23.2 \\
\hline Secondary and higher level & 93 & 23.2 \\
\hline \multicolumn{3}{|c|}{ Education status of husband $(n=254)$} \\
\hline Illiterate & 54 & 13.5 \\
\hline Primary level & 85 & 21.2 \\
\hline Secondary and higher level & 115 & 28.7 \\
\hline \multicolumn{3}{|l|}{ Residence } \\
\hline Urban & 275 & 68.6 \\
\hline Rural & 126 & 31.4 \\
\hline \multicolumn{3}{|l|}{ Occupation } \\
\hline Employment & 77 & 19.2 \\
\hline Unemployment & 324 & 80.8 \\
\hline \multicolumn{3}{|l|}{ Socioeconomic status } \\
\hline Low & 325 & 81 \\
\hline Moderate & 69 & 17.3 \\
\hline High & 7 & 1.7 \\
\hline \multicolumn{3}{|l|}{ Social security } \\
\hline Yes & 391 & 97.5 \\
\hline No & 10 & 2.5 \\
\hline \multicolumn{3}{|c|}{ Distance to the first consultation $(\mathrm{Km})$} \\
\hline$\leq 3 \mathrm{~km}$ & 315 & 78.6 \\
\hline$[3-6[$ & 17 & 4.2 \\
\hline$[6-10[$ & 36 & 9.0 \\
\hline$\geq 10$ & 33 & 8.2 \\
\hline \multicolumn{3}{|l|}{ Medical history } \\
\hline Yes & 105 & 25 \\
\hline \multicolumn{3}{|l|}{ Type of earlier symptoms } \\
\hline \multicolumn{3}{|c|}{$\begin{array}{l}\text { Abnormal vaginal bleeding (between periods, } \\
\text { after sex, postmenopausal) }\end{array}$} \\
\hline Yes & 264 & 65,8 \\
\hline \multicolumn{3}{|l|}{ Vaginal discharge } \\
\hline Yes & 69 & 17,2 \\
\hline \multicolumn{3}{|c|}{ Pain (painful sex, pelvic pain, dysuria) } \\
\hline Yes & 139 & 34,6 \\
\hline \multicolumn{3}{|l|}{ Personal history of cancer } \\
\hline Yes & 3 & 0.7 \\
\hline
\end{tabular}

TABLE 1: Continued.

\begin{tabular}{lcc}
\hline Characteristics & $n$ & $\%$ \\
\hline Family history of cancer & & \\
Yes & 41 & 10.2 \\
Histopathology & 349 & 87 \\
Squamous cell & 52 & 13 \\
Adenocarcinoma & & \\
Stage at diagnosis & 241 & 60.1 \\
IIA-IIB & 145 & 36.2 \\
IIIA-IIIB & 15 & 3.7 \\
IVA-IVB & & \\
Patient delay (days) & 179 & 44.6 \\
$\leq 90$ & 222 & 55.4 \\
\hline 90 & &
\end{tabular}

bleeding as cervical cancer symptoms. Greater proportion $(90.3 \%)$ did not have any idea about causes of cervical cancer. $51.6 \%$ of cases have never heard about screening program and $74.1 \%$ did not know transmission mode. More than half $(58.9 \%)$ of patients have never done a pap smear test and $55.9 \%$ did not have a gynecologic examination during last three years and $82 \%$ have never done a screening test (Table 2).

The association between sociodemographic characteristics and patient delay is presented in Table 3. A wide variety of variables were associated univariately with patient delay such as age (adjusted OR $=0.509, \mathrm{CI}: 0.341-0.759, p<0.001$ ) and level of education as protector factors, respectively, for primary and secondary and high level (adjusted OR $=0.430$, CI: $0.259-0.713, p<0.001$, adjusted OR $=0.071$, CI: $0.038-$ $0.133, p<0.001)$. The secondary and higher level of husband education was also found as a protector factor (adjusted OR $=0.176$, CI: $0.085-0.365, p<0.001)$. Rural residence was considered as a risk factor (adjusted OR $=1.888, \mathrm{CI}$ : $1.219-$ 2.925, $p=0.004)$. Occupation was considered as a protector factor (adjusted OR $=0.439, \mathrm{CI}: 0.264-0.730, p=0.002$ ). Low socioeconomic status was found as a risk factor for patient delay (adjusted OR $=3.927, \mathrm{CI}: 2.280-6.765, p<0.001$ ) and remoteness more than $6 \mathrm{~km}$ for the first consultation was found as a risk factor $(p<0.05)$.

After multivariate analysis, only literacy status of women and remoteness of place of first consultation were found significantly associated with patient delay. Lower risk of patient delay was observed for women who were literate $(p<$ 0.001 ) but high risk was observed for patients who were more than $10 \mathrm{~km}$ far from the first consultation (adjusted $\mathrm{OR}=1.68$, CI: $1.08-2.60, p=0.02$ ).

The association between clinical variables and patient delay is presented in Table 4. All variables which were statically significant on univariate analyses at $p$ ( 0.20 levels) were included in multivariate analysis. Abnormal vaginal bleeding as an earlier symptom was found as a protector factor (adjusted OR $=0.345$, CI: 0.218-0.548, $p<0.001$ ). Stages III and IV at diagnosis were found as a risk factor for 
TABLE 2: Description of knowledge and practice in cervical cancer $(n=401)$.

\begin{tabular}{|c|c|c|}
\hline Characteristics & $n$ & $\%$ \\
\hline \multicolumn{3}{|c|}{ knowledge of cervical cancer } \\
\hline Yes & 205 & 51.1 \\
\hline \multicolumn{3}{|c|}{ Knowledge of symptoms } \\
\hline \multicolumn{3}{|c|}{$\begin{array}{l}\text { Abnormal vaginal bleeding (between periods, } \\
\text { after sex, postmenopausal) }\end{array}$} \\
\hline Yes & 158 & 39.6 \\
\hline \multicolumn{3}{|l|}{ Vaginal discharge } \\
\hline Yes & 71 & 82.3 \\
\hline \multicolumn{3}{|c|}{ Pain (painful sex, pelvic pain, dysuria) } \\
\hline Yes & 102 & 25.7 \\
\hline \multicolumn{3}{|l|}{ Knowledge of causes } \\
\hline Yes & 39 & 9.7 \\
\hline \multicolumn{3}{|c|}{ Knowledge of transmission mode } \\
\hline Yes & 104 & 25.9 \\
\hline \multicolumn{3}{|c|}{ Knowledge of screening program } \\
\hline Yes & 194 & 48.4 \\
\hline \multicolumn{3}{|c|}{ Knowledge of HPV vaccine } \\
\hline Yes & 45 & 11.2 \\
\hline \multicolumn{3}{|c|}{ Knowledge of treatment } \\
\hline Yes & 267 & 66.5 \\
\hline \multicolumn{3}{|l|}{ History of pap smear } \\
\hline Never & 236 & 58.9 \\
\hline More than 3 years & 105 & 26.1 \\
\hline During last 3 years & 60 & 15 \\
\hline \multicolumn{3}{|c|}{$\begin{array}{l}\text { Practice of gynecological examination during last } 3 \\
\text { years }\end{array}$} \\
\hline Yes & 177 & 44.1 \\
\hline \multicolumn{3}{|c|}{$\begin{array}{l}\text { Practice of screening test by visual inspection with } \\
\text { acetic acid (VIA) }\end{array}$} \\
\hline Yes & 72 & 18 \\
\hline
\end{tabular}

patient delay (adjusted OR $=2.113, \mathrm{CI}: 1.348-3.314, p<0.001$, adjusted OR $=11.439, \mathrm{CI}: 1.431-91.443, p=0.022)$.

The association between knowledge and practice in cervical cancer and patient delay is summarized in Table 5. Bivariate analysis showed that patients with no knowledge of cervical cancer $(p<0.0001)$, symptoms $(p<0.0001)$, causes $(p<0.0001)$, screening program $(p<0.0001)$, transmission mode $(p=0.0001)$, and treatment $(p<0.0001)$ were more likely to delay.

Furthermore, patients who have already made a pap smear $(p<0.0001)$ were less likely to delay. But patients who did not practice a gynecological examination during the last 3 years $(p<0.0001)$ and screening test $(p<0.0001)$ were more likely to delay.

The multivariate comparison of those factors showed that knowledge of abnormal vaginal bleeding as a symptom was found as a protective factor (adjusted OR $=0.069$, CI: $0.020-$ $0.231, p<0.001)$ compared to the vaginal discharge and pain. Knowledge of causes was found also as a protective factor (adjusted OR $=0.094, \mathrm{CI}: 0.016-0.546, p=0.008$ ). Women were more likely to delay if they did not practice a gynecological examination during the last 3 years (adjusted $\mathrm{OR}=4.517$, CI: $1.295-15.762, p=0.018)$.

\section{Discussion}

This paper is the first that studied knowledge and practice as determinants of patient delay in women with cervical cancer in Morocco. Four hundred and one (401) patients with cervical cancer enrolled in this study. Two hundred and twenty-two (55.4\%) were found having patient delay. The rate indicated the necessity of general screening program or improvement of population awareness in this regard.

The present findings are consistent with a research conducted in Morocco showing that sixty percent $(60 \%)$ of women had a patient delay [9].

Among the sociodemographic characteristics of patients, education status of women was found significantly associated with patient delay. Lower risk of patient delay was observed for women who were literate. This result is in agreement with some studies $[9,16,17]$, but in contrast with others $[18,19]$.

Our study did not demonstrate association between age, health insurance, place of residence, and patient delay. A study conducted in Sudan [20] has shown that older age is a predictor for patient delay. This study investigated also the association between rural residence, not having insurance, and delay at presentation of cervical cancer.

The findings showed that remoteness of place of the first consultation was found significantly associated with patient delay. High risk was observed for patients who were $3 \mathrm{~km}$ and more far from the first consultation. Our results concur closely with the available data in the literature $[9,11,21]$.

While our findings are consistent with some studies, they were in contrast with others. A study conducted in China indicated that being unmarried was the high risk factor for delayed reporting of cervical cancer [22].

Of the 401 patients studied, 160 (39.9\%) presented with stage III or IV disease of which 110 have presented a patient delay. This could be due to excessive delay that allowed the progression of the disease to advanced stage. The advanced stage at presentation might be due to the fact that most cancer in low- and middle-income countries is detected at later stages. There was a significant association between patient delay and late stage at presentation. The present study is consistent with a previous study conducted in Uganda by Galukande et al. that show that patient delay is more prevalent in patients with advanced stage at presentation [23].

This study revealed that women having abnormal vaginal bleeding such as postcoital bleeding, intermenstrual bleeding, or postmenopausal bleeding as early symptom were less likely to have patient delay. This can be explained by the fact that gynecological bleeding is usually perceived as more urgent than gynecological infection or pelvic pain. Women usually tend to ignore the mild gynecological symptoms such as vaginal discharge considering it as a general problem until it becomes warning symptoms such as vaginal bleeding [24]. 
TABLE 3: Associations between delayed reporting demographic and socioeconomic variables.

\begin{tabular}{|c|c|c|c|c|c|c|c|c|}
\hline \multirow{2}{*}{ Categorial variables } & \multirow{2}{*}{$\begin{array}{c}\leq 90 \text { days } \\
(n=179) \\
n(\%)\end{array}$} & \multirow{2}{*}{$\begin{array}{c}>90 \text { days } \\
(n=222) \\
n(\%)\end{array}$} & \multicolumn{3}{|c|}{ Univariate analysis } & \multicolumn{3}{|c|}{ Multivariate analysis } \\
\hline & & & OR & $95 \% \mathrm{CI}$ & $p$ & OR & $95 \%$ CI & $p$ \\
\hline \multicolumn{9}{|l|}{ Age (year) } \\
\hline$\leq 50$ & $100(53.5)$ & $87(46.5)$ & 0.509 & [0.341-0.759] & $0.001^{*}$ & 0.802 & {$[0.817-3.977]$} & 0.145 \\
\hline$>50$ & $79(36.9)$ & $135(63.1)$ & & & & & & \\
\hline \multicolumn{9}{|l|}{ Marital status } \\
\hline Married & $114(44.9)$ & $140(55.1)$ & & & & & & \\
\hline Unmarried & $65(44.2)$ & $82(55.8)$ & 1.027 & {$[0.683-1.546]$} & 0.897 & & & \\
\hline \multicolumn{9}{|l|}{ Education status } \\
\hline Illiterate & $58(27)$ & $157(73)$ & & & & & & \\
\hline Primary level & $43(46.2)$ & $50(53.8)$ & 0.430 & [0.259-0.713] & $0.001^{*}$ & 0.239 & {$[0.099-0.574]$} & $0.001^{* *}$ \\
\hline Secondary and higher level & $78(83.9)$ & $15(16.1)$ & 0.071 & {$[0.038-0.133]$} & $0.001^{*}$ & 0.026 & {$[0.007-0.095]$} & $0.001^{* *}$ \\
\hline \multicolumn{9}{|l|}{ Education status of husband } \\
\hline Illiterate & $13(24.1)$ & $41(75.9)$ & & & & & & \\
\hline Primary level & $27(31.8)$ & $58(68.2)$ & 0.681 & {$[0.314-1.476]$} & 0.330 & 0.845 & {$[0.367-1.948]$} & 0.693 \\
\hline Secondary and higher level & $74(64.3)$ & $41(35.7)$ & 0.176 & {$[0.085-0.365]$} & $0.001^{*}$ & 1.219 & {$[0.421-3.529]$} & 0.715 \\
\hline \multicolumn{9}{|l|}{ Residence } \\
\hline Urban & $136(49.5)$ & $139(50.5)$ & & & & & & \\
\hline Rural & $43(43.1)$ & $83(65.9)$ & 1.888 & {$[1.219-2.925]$} & $0.004^{*}$ & 0.451 & {$[0.178-1.146]$} & 0.094 \\
\hline \multicolumn{9}{|l|}{ Occupation } \\
\hline Employed & $47(61)$ & $30(39)$ & & & & & & \\
\hline Unemployed & $132(46.7)$ & $192(59.3)$ & 0.439 & {$[0.264-0.730]$} & $0.002^{*}$ & 1.528 & {$[0.496-4.708]$} & 0.461 \\
\hline \multicolumn{9}{|l|}{ Socioeconomic status } \\
\hline Low & $125(38.5)$ & $200(61.5)$ & 3.927 & {$[2.280-6.765]$} & $0.001^{*}$ & 1.525 & {$[0.606-3.841]$} & 0.370 \\
\hline Moderate and high & $54(71.1)$ & $22(28.9)$ & & & & & & \\
\hline \multicolumn{9}{|l|}{ Social security } \\
\hline Yes & $173(44.2)$ & $218(55.8)$ & & & & & & \\
\hline No & $6(60)$ & $4(40)$ & 0.529 & {$[0.147-1.904]$} & 0.330 & & & \\
\hline \multicolumn{9}{|c|}{ Distance to the first consultation $(\mathrm{Km})$} \\
\hline$<3$ & $155(49.2)$ & $160(50.8)$ & & & & & & \\
\hline$[3-6[$ & $5(29.4)$ & $12(70.6)$ & 2.325 & {$[0.800-6.754]$} & $0.121^{*}$ & 2.953 & {$[0.262-33.248]$} & 0.381 \\
\hline$[6-10[$ & $6(25)$ & $27(75)$ & 2.906 & [1.324-6.378] & $0.008^{*}$ & 2.720 & {$[0.758-9.770]$} & 0.125 \\
\hline$\geq 10$ & $10(30.3)$ & $23(69.7)$ & 2.228 & {$[1.027-4.834]$} & $0.043^{*}$ & 4.943 & [1.162-21.035] & $0.031^{* *}$ \\
\hline
\end{tabular}

${ }^{*}$ Model included variables that were significant on univariate analyses at $p$ (0.20 level).

${ }^{* *}$ Significant at $p$ value $\leq 0.05$.

Patients were typically less likely to delay if they experienced a more serious symptom, such an alarming symptom like bleeding. These findings are further corroborated with a study conducted in Morocco, where increased risks for patient delay were observed in women who did not have vaginal bleeding as the first symptom [9].

The patients who lacked knowledge on cervical cancer and its symptoms were at risk for patient delay. The low levels of symptom awareness may partly explain why the type of symptom is consistent with risk factors for delayed patient presentation [25]. Patients may fail to recognize or appreciate atypical or vague symptoms, which may mediate delayed presentation. A systematic review that examined the risk factors for delayed presentation in cancer found that nonrecognition of symptom type and infrequent care-seeking were the predominant risk factors for delayed presentation for gynecological cancers [23]. Many other studies have identified knowledge, availability, or lack, thereof, as a factor influencing access to health care services [26, 27].

In the current study, greater patient delay risk was found among patients who did not practice a gynecological examination during last 3 years. There was evidence that regular visits to medical practitioners, including attendance for routine screening, were associated with shorter delay in patients with gynecological cancers [28]. A study conducted in Iran by Behnamfar and Azadehrah found that history of 
TABLE 4: Association between clinical factors and patient delay, identified by multivariate analysis.

\begin{tabular}{|c|c|c|c|c|c|c|c|c|}
\hline \multirow[t]{2}{*}{ Categorial variables } & \multirow{2}{*}{$\begin{array}{c}\leq 90 \text { days } \\
(n=179) \\
n(\%)\end{array}$} & \multirow{2}{*}{$\begin{array}{c}>90 \text { days } \\
(n=222) \\
n(\%)\end{array}$} & \multicolumn{3}{|c|}{ Univariate analysis } & \multicolumn{3}{|c|}{ Multivariate analysis } \\
\hline & & & OR & 95\% CI & $p$ & OR & $95 \% \mathrm{CI}$ & $p$ \\
\hline \multicolumn{9}{|l|}{ Medical history } \\
\hline Yes & $52(50)$ & $52(50)$ & & & & & & \\
\hline No & $127(42.8)$ & $170(57.2)$ & 1.339 & [0.855-2.095] & $0.202^{*}$ & 1.332 & [0.827-2.145] & 0.238 \\
\hline \multicolumn{9}{|l|}{ Earlier symptoms } \\
\hline \multicolumn{9}{|l|}{$\begin{array}{l}\text { Abnormal vaginal } \\
\text { bleeding (between } \\
\text { periods, after sex, } \\
\text { postmenopausal) }\end{array}$} \\
\hline Yes & $158(46,3)$ & $183(53,7)$ & 0.335 & {$[0.214-0.523]$} & $0.001^{*}$ & 0.345 & {$[0.218-0.548]$} & $0.001^{* *}$ \\
\hline No & $21(35)$ & $39(65)$ & & & & & & \\
\hline \multicolumn{9}{|l|}{ Vaginal discharge } \\
\hline Yes & $31(50)$ & $31(50)$ & & & & & & \\
\hline No & $148(43,7)$ & $191(56,3)$ & 1.014 & [0.602-1.708] & 0.958 & & & \\
\hline \multicolumn{9}{|l|}{$\begin{array}{l}\text { Pain (painful sex, } \\
\text { pelvic pain, dysuria) }\end{array}$} \\
\hline Yes & $92(39.8)$ & $139(60.2)$ & & & & & & \\
\hline No & $87(51.2)$ & $83(48.8)$ & 0.631 & {$[0.423-0.942]$} & $0.024^{*}$ & 1.255 & {$[0.812-1.940]$} & 0.307 \\
\hline \multicolumn{9}{|l|}{$\begin{array}{l}\text { Personal history of } \\
\text { cancer }\end{array}$} \\
\hline Yes & $2(66.7)$ & $1(33.3)$ & & & & & & \\
\hline No & $177(44.5)$ & $221(55.5)$ & 2.497 & {$[0.225-27.760]$} & 0.456 & & & \\
\hline \multicolumn{9}{|l|}{$\begin{array}{l}\text { Family history of } \\
\text { cancer }\end{array}$} \\
\hline Yes & $23(56.1)$ & $18(43.9)$ & & & & & & \\
\hline No & $156(43.3)$ & $204(56.7)$ & 1.671 & [0.871-3.204] & $0.122^{*}$ & 1.630 & {$[0.812-3.272]$} & 0.170 \\
\hline \multicolumn{9}{|l|}{ Histopathology } \\
\hline Squamous cell & $157(45)$ & $192(55)$ & & & & & & \\
\hline Adenocarcinoma & $22(42.3)$ & $30(57.7)$ & 1.115 & [0.619-2.010] & 0.717 & & & \\
\hline \multicolumn{9}{|l|}{ Stage at diagnosis } \\
\hline IIA-IIB & $129(53.5)$ & $112(46.5)$ & & & & & & \\
\hline IIIA-IIIB & $49(33.8)$ & $96(66.2)$ & 2.257 & {$[1.472-3.459]$} & $0.001^{*}$ & 2.113 & {$[1.348-3.314]$} & $0.001^{* *}$ \\
\hline IVA-IVB & $1(6.7)$ & $14(93.3)$ & 16.121 & [2.087-124.507] & $0.008^{*}$ & 11.439 & [1.431-91.443] & $0.022^{* *}$ \\
\hline
\end{tabular}

${ }^{*}$ Model included variables that were significant on univariate analyses at $p(0.20$ level).

${ }^{* *}$ Significant at $p$ value $\leq 0.05$.

pap smear had significant association with delay at presentation [29], even though our findings did not demonstrate this association.

The respondents showed a somewhat poor knowledge of causes of cervical cancer with $90.3 \%$ respondents admitting they do not know what causes the disease; some even after having the disease for several years they still did not know about the HPV virus. The others believed that cervical cancer was due to a variety of factors even though a few patients knew it was sexually transmitted. Similar findings were noted by other studies carried out in India and Maldives [30, 31].

In the present study, over half (55.4\%) of the patients with cervical cancer were over 90 days to check for symptoms and reported patient delay. Such a high proportion may be explained by the fact that knowledge level can determine the kind of action one may take which could be either negative or positive. It is important not to lose sight of the fact that low knowledge about cervical cancer potentially precludes uptake of early presentation [32]

The determinants of patient delay can be different in different places. One explanation for such a difference might relate to the socioeconomic context where patients live.

However, due to the amalgamation of many factors that lead to patient's delay, prevention interventions should focus on targeted women to promote early presentation. Although in Morocco a nationwide program for early detection of cervical cancer was implemented in 2010 using visual inspection with acetic acid (VIA) as the screening tool several challenges to national scale-up were detected such as low compliance with the screening program. A national awareness campaign 
TABLE 5: Association between knowledge and practice and patient delay identified by multivariate analysis.

\begin{tabular}{|c|c|c|c|c|c|c|c|c|}
\hline \multirow{2}{*}{ Categorial variables } & \multirow{2}{*}{$\begin{array}{c}\leq 90(n=179) \\
n(\%)\end{array}$} & \multirow{2}{*}{$\begin{array}{c}>90(n=222) \\
n(\%)\end{array}$} & \multicolumn{3}{|c|}{ Univariate analysis } & \multicolumn{3}{|c|}{ Multivariate analysis } \\
\hline & & & OR & $95 \%$ CI & $p$ & OR & $95 \%$ CI & $p$ \\
\hline \multicolumn{9}{|l|}{$\begin{array}{l}\text { Previously heard } \\
\text { about cervical cancer }\end{array}$} \\
\hline Yes & $155(75.6)$ & $50(24.4)$ & & & & & & \\
\hline No & $24(12.2)$ & $172(87.8)$ & 22.217 & [13.039-37.855] & $0.001^{*}$ & 2.707 & [0.834-8.753] & 0.098 \\
\hline \multicolumn{9}{|l|}{$\begin{array}{l}\text { Knowledge of } \\
\text { symptoms }\end{array}$} \\
\hline \multicolumn{9}{|l|}{$\begin{array}{l}\text { Abnormal vaginal } \\
\text { bleeding (between } \\
\text { periods, after sex, } \\
\text { postmenopausal) }\end{array}$} \\
\hline Yes & $141(89.8)$ & $16(10.2)$ & 0.020 & [0.011-0.038] & $0.001^{*}$ & 0.069 & {$[0.020-0.231]$} & $0.001^{* *}$ \\
\hline No & $37(15.2)$ & $206(84.4)$ & & & & & & \\
\hline \multicolumn{9}{|l|}{ Vaginal discharge } \\
\hline Yes & $60(84.5)$ & $11(15.5)$ & & & & & & \\
\hline No & $119(36.1)$ & $211(63.9)$ & 9.969 & [4.894-19.102] & $0.001^{*}$ & 0.874 & [0.284-2.692] & 0.814 \\
\hline \multicolumn{9}{|l|}{$\begin{array}{l}\text { Pain (painful sex, } \\
\text { pelvic pain, dysuria) }\end{array}$} \\
\hline Yes & $93(89.4)$ & $11(10.6)$ & & & & & & \\
\hline No & $86(29)$ & $211(71)$ & 20.743 & {$[10.579-40.673]$} & $0.001^{*}$ & 1.956 & {$[0.483-7.926]$} & 0.347 \\
\hline \multicolumn{9}{|l|}{ Knowledge of causes } \\
\hline Yes & $40(95.2)$ & $2(4.8)$ & 0.032 & {$[0.008-0.133]$} & $0.001^{*}$ & 0.094 & {$[0.016-0.546]$} & $0.008^{* *}$ \\
\hline No & $139(38.7)$ & $220(61.3)$ & & & & & & \\
\hline \multicolumn{9}{|l|}{$\begin{array}{l}\text { Knowledge of } \\
\text { Screening program }\end{array}$} \\
\hline Yes & $142(73.2)$ & $52(26.8)$ & & & & & & \\
\hline No & $37(17.9)$ & $170(82.1)$ & 12.546 & {$[7.788-20.210]$} & $0.001^{*}$ & 0.861 & {$[0.262-2.829]$} & 0.805 \\
\hline \multicolumn{9}{|l|}{$\begin{array}{l}\text { Knowledge of } \\
\text { transmission mode }\end{array}$} \\
\hline Yes & $83(79.8)$ & $21(20.2)$ & & & & & & \\
\hline No & $96(32.3)$ & $201(67.7)$ & 8.275 & [4.837-14.157] & $0.001^{*}$ & 0.687 & {$[0.258-1.831]$} & 0.453 \\
\hline \multicolumn{9}{|l|}{$\begin{array}{l}\text { Knowledge of } \\
\text { treatment }\end{array}$} \\
\hline Yes & $138(51.7)$ & $129(48.3)$ & & & & & & \\
\hline No & $41(30.6)$ & $93(69.4)$ & 2.426 & {$[1.564-3.762]$} & $0.001^{*}$ & 0.488 & [0.225-1.057] & 0.069 \\
\hline \multicolumn{9}{|l|}{ History of pap smear } \\
\hline Never & $37(15.7)$ & $199(84.3)$ & & & & & & \\
\hline More than 3 years & $86(81.9)$ & $19(18.1)$ & 0.041 & {$[0.022-0.075]$} & $0.001^{*}$ & 0.629 & {$[0.168-2.361]$} & 0.492 \\
\hline During last 3 years & $56(93.3)$ & $4(6.7)$ & 0.013 & {$[0.005-0.039]$} & $0.001^{*}$ & 0.338 & [0.064-1.792] & 0.202 \\
\hline \multicolumn{9}{|l|}{$\begin{array}{l}\text { Gynecological } \\
\text { examination during } \\
\text { last } 3 \text { years }\end{array}$} \\
\hline Yes & $149(84.2)$ & $28(15.8)$ & & & & & & \\
\hline No & $30(13.4)$ & $194(86.6)$ & 34.412 & [19.705-60.095] & $0.001^{*}$ & 4.517 & [1.295-15.762] & $0.018^{* *}$ \\
\hline \multicolumn{9}{|l|}{$\begin{array}{l}\text { Practice of screening } \\
\text { test }\end{array}$} \\
\hline Yes & $63(87.5)$ & $9(12.5)$ & & & & & & \\
\hline No & $116(35.3)$ & $213(64.7)$ & 12.836 & {$[6.162-26.737]$} & $0.001^{*}$ & 2.430 & {$[0.757-7.804]$} & 0.136 \\
\hline
\end{tabular}

${ }^{*}$ Model included variables that were significant on univariate analyses at $p(0.20$ level $)$.

*** significant at $p$ value $\leq 0.05$. 
and mass communication are required to improve screening participation [33].

Further research is needed to clarify relevant other risk factors for delayed time to presentation for some particularly underresearched cancers, such as cervical cancer.

This study was not free of limitations. It is a crosssectional design and constituted of patients attending a tertiary hospital in the country capital and hence it might not be representative of all the Moroccan patients affected by cervical cancer. Also, the duration of symptoms which were described by the patients might be biased.

\section{Conclusion}

This study sought determinants of the patient delay in women with cervical cancer. The findings point to poor knowledge among most Moroccan patients on the actual nature of cervical cancer, its symptoms, and causes. Most of the women did not know about cervical cancer prior to their diagnosis. Knowledge of cervical cancer and practice of examination are important elements in determining whether women will take preventive measures against the disease. Educational messages to the general population should aim at increasing awareness of cervical cancer, assisting women in symptom recognition, and encouraging earlier presentation. It seems that in order to achieve more conclusive results further studies with prospective design are needed.

\section{Competing Interests}

Authors disclose no potential conflict of interests.

\section{Authors' Contributions}

This work was carried out with collaboration between all authors. Fatima Ouasmani, Abdelhalem Mesfioui, and Samir Ahid jointly developed the structure and arguments for the paper. Fatima Ouasmani collected data, performed the data analysis, and wrote the first draft. Fatima Ouasmani and Samir Ahid contributed to the manuscript results and conclusions. Abdelhalem Mesfioui, Zaki Hanchi, Samir Ahid, and Bouchra Haddou Rahou performed critical reviews for important intellectual content of the manuscript. Rachid Bekkali made critical revision and approved final version. All authors read and approved the final manuscript.

\section{Acknowledgments}

The authors are grateful to all patients and their families; all health professionals at the National Institute of Oncology Sidi Mohammed Ben Abdellah in Rabat, Morocco; Lalla Salma Foundation-Prevention and Treatment of Cancers, for their continued support for students and researchers; Dr. Ahmed Zidouh for his valuable guidance.

\section{References}

[1] J. Ferlay, H.-R. Shin, F. Bray, D. Forman, C. Mathers, and D. M. Parkin, "Estimates of worldwide burden of cancer in 2008: GLOBOCAN 2008," International Journal of Cancer, vol. 127, no. 12, pp. 2893-2917, 2010.

[2] B. C. R. Devi, T. S. Tang, and M. Corbex, "Reducing by half the percentage of late-stage presentation for breast and cervix cancer over 4 years: a pilot study of clinical downstaging in Sarawak, Malaysia," Annals of Oncology, vol. 18, no. 7, pp. 11721176, 2007.

[3] C. S. Thomson and D. Forman, "Cancer survival in England and the influence of early diagnosis: what can we learn from recent EUROCARE results," British Journal of Cancer, vol. 101, supplement 2, pp. S102-S109, 2009.

[4] E. Chadza, E. Chirwa, A. Maluwa, A. Malata, A. Kazembe, and A. Chimwaza, "Factors that contribute to delay in seeking cervical cancer diagnosis and treatment among women in Malawi," Health, vol. 04, no. 11, pp. 1015-1022, 2012.

[5] V. L. Allgar and R. D. Neal, "Delays in the diagnosis of six cancers: analysis of data from the national survey of NHS patients: cancer," British Journal of Cancer, vol. 92, no. 11, pp. 1959-1970, 2005.

[6] V. Vinh-Hung, C. Bourgain, G. Vlastos et al., "Prognostic value of histopathology and trends in cervical cancer: a SEER population study," BMC Cancer, vol. 7, article 164, 2007.

[7] M. Berraho, K. Bendahhou, M. Obtel et al., "Cervical cancer in Morocco: epidemiological profile from two main oncological centers," Asian Pacific Journal of Cancer Prevention, vol. 13, no. 7, pp. 3153-3157, 2012.

[8] L. Bruni, R. L. Barrionuevo, G. Albero et al., Human Papillomavirus and Related Diseases in Morocco, ICO Information Centre on HPV and Cancer, Summary Report, 2016.

[9] M. Berraho, M. Obtel, K. Bendahhou et al., "Sociodemographic factors and delay in the diagnosis of cervical cancer in Morocco," The Pan African medical journal, vol. 12, article 14, 2012.

[10] F. Khorasanizadeh, J. Hassanloo, N. Khaksar et al., "Epidemiology of cervical cancer and human papilloma virus infection among Iranian women-analyses of national data and systematic review of the literature," Gynecologic Oncology, vol. 128, no. 2, pp. 277-281, 2013.

[11] D. Gyenwali, J. Pariyar, and S. R. Onta, "Factors associated with late diagnosis of cervical cancer in Nepal," Asian Pacific Journal of Cancer Prevention, vol. 14, no. 7, pp. 4373-4377, 2013.

[12] R. P. Hansen, F. Olesen, H. T. Sørensen, I. Sokolowski, and J. Søndergaard, "Socioeconomic patient characteristics predict delay in cancer diagnosis: A Danish Cohort Study," BMC Health Services Research, vol. 8, article 49, 2008.

[13] S. Pecorelli, J. L. Benedet, W. T. Creasman et al., "FIGO staging of gynecologic cancer. 1994-1997 FIGO Committees on Gynecologic Oncology. International Federation of Gynecology and Obstetrics," International Journal of Gynecology \& Obstetrics, vol. 65, no. 3, pp. 243-249, 1999.

[14] D. Schwartz, Méthodes Statistiques à L'usage des Médecins et Biologistes, Flammarion Médecins Sciences, 1969.

[15] G. T. Pack and J. S. Gallo, "The culpability for delay in the treatment of cancer," American Journal of Cancer, vol. 33, no. 3, pp. 443-462, 1938.

[16] S. Franceschi, M. Plummer, G. Clifford et al., "Differences in the risk of cervical cancer and human papillomavirus infection 
by education level," British Journal of Cancer, vol. 101, no. 5, pp. 865-870, 2009.

[17] A. V. Lourenço, C. M. S. Fregnani, P. C. S. Silva, M. R. D. O. Latorre, and J. H. T. G. Fregnani, "Why are women with cervical cancer not being diagnosed in preinvasive phase?: an analysis of risk factors using a hierarchical model," International Journal of Gynecological Cancer, vol. 22, no. 4, pp. 645-653, 2012.

[18] S. Dhamija, A. Sehgal, U. K. Luthra, and K. Sehgal, "Factors associated with awareness and knowledge of cervical cancer in a community: implication for health education programmes in developing countries," Journal of the Royal Society of Health, vol. 113, no. 4, pp. 184-186, 1993.

[19] B. L. Andersen, J. T. Cacioppo, and D. C. Roberts, "Delay in seeking a cancer diagnosis: delay stages and psychophysiological comparison processes," British Journal of Social Psychology, vol. 34, no. 1, pp. 33-52, 1995.

[20] A. Ibrahim, V. Rasch, E. Pukkala, and A. R. Aro, "Predictors of cervical cancer being at an advanced stage at diagnosis in Sudan," International Journal of Women's Health, vol. 3, no. 1, pp. 385-389, 2011.

[21] M. Kaku, A. Mathew, and B. Rajan, "Impact of socio-economic factors in delayed reporting and late-stage presentation among patients with cervix cancer in a major cancer hospital in South India," Asian Pacific Journal of Cancer Prevention, vol. 9, no. 4, pp. 589-594, 2008.

[22] J. Ma, Q. Zhu, S. Han et al., "Effect of socio-economic factors on delayed access to health care among Chinese cervical cancer patients with late rectal complications after radiotherapy," Gynecologic Oncology, vol. 124, no. 3, pp. 395-398, 2012.

[23] M. Galukande, F. Mirembe, and H. Wabinga, "Patient delay in accessing breast cancer care in a sub saharan African Country: Uganda," British Journal of Medicine and Medical Research, vol. 4, no. 13, pp. 2599-2610, 2014.

[24] U. MacLeod, E. D. Mitchell, C. Burgess, S. MacDonald, and A. J. Ramirez, "Risk factors for delayed presentation and referral of symptomatic cancer: evidence for common cancers," British Journal of Cancer, vol. 101, supplement 2, pp. S92-S101, 2009.

[25] S. Macdonald, U. Macleod, E. Mitchell et al., "Factors influencing patient and primary care delay in the diagnosis of cancer: a database of existing research and its implications for future practice," Tech. Rep., UK Department of Health, University of Glasgow, Glasgow, UK, 2004.

[26] P. Gichangi, B. Estambale, J. Bwayo et al., "Knowledge and practice about cervical cancer and Pap smear testing among patients at Kenyatta National Hospital, Nairobi, Kenya," International Journal of Gynecological Cancer, vol. 13, no. 6, pp. 827-833, 2003.

[27] S. Aswathy, M. A. Quereshi, B. Kurian, and K. Leelamoni, "Cervical cancer screening: current knowledge \& practice among women in a rural population of Kerala, India," Indian Journal of Medical Research, vol. 136, no. 2, pp. 205-210, 2012.

[28] R. Menon, A. Sehgal, V. Singh, N. S. Murthy, and U. K. Luthra, "Medical attention-seeking behaviour of cervical cancer patients. Implication for cervical cancer control in developing countries," Cancer Journal, vol. 4, no. 3, pp. 202-205, 1991.

[29] F. Behnamfar and M. Azadehrah, "Factors associated with delayed diagnosis of cervical cancer in Iran-a survey in Isfahan City," Asian Pacific Journal of Cancer Prevention, vol. 16, no. 2, pp. 635-639, 2015.

[30] A. Saha, A. Nag Chaudhury, P. Bhowmik, and R. Chatterjee, "Awareness of cervical cancer among female students of premier colleges in Kolkata, India," Asian Pacific Journal of Cancer Prevention, vol. 11, no. 4, pp. 1085-1090, 2010.
[31] P. Basu, S. Hassan, F. Fileeshia et al., "Knowledge, attitude and practices of women in Maldives related to the risk factors, prevention and early detection of cervical cancer," Asian Pacific Journal of Cancer Prevention, vol. 15, no. 16, pp. 6691-6695, 2014.

[32] A. E. Simon, J. Waller, K. Robb, and J. Wardle, "Patient delay in presentation of possible cancer symptoms: the contribution of knowledge and attitudes in a population sample from the United Kingdom," Cancer Epidemiology Biomarkers and Prevention, vol. 19, no. 9, pp. 2272-2277, 2010.

[33] F. Selmouni, C. Sauvaget, L. Belakhel, E. Lucas, M. Khouchoua, and R. Sankaranarayanan, "Organization and evaluation of a pilot cervical cancer screening program in Morocco," International Journal of Gynecology and Obstetrics, vol. 132, no. 1, pp. 25-28, 2016. 


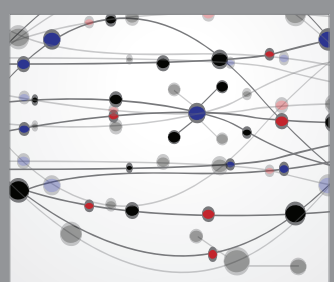

The Scientific World Journal
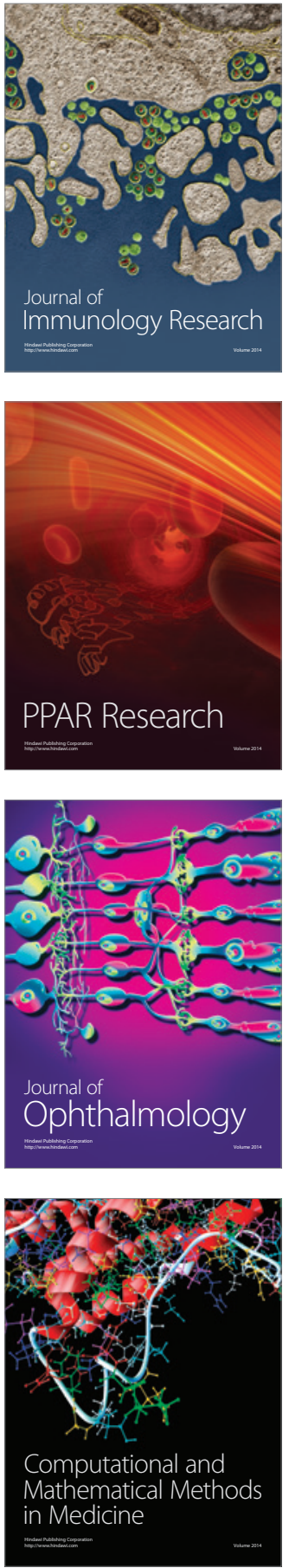

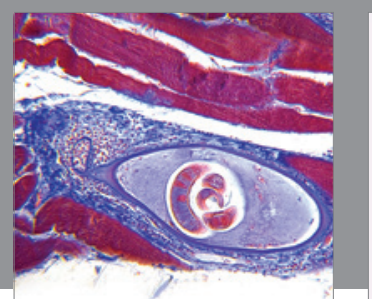

Gastroenterology Research and Practice

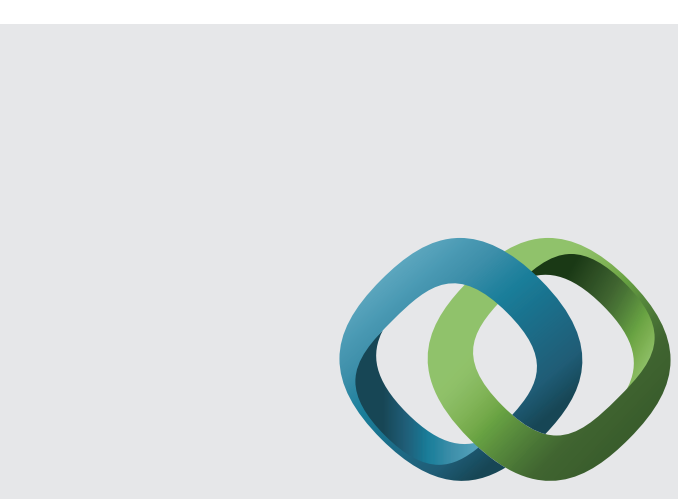

\section{Hindawi}

Submit your manuscripts at

http://www.hindawi.com
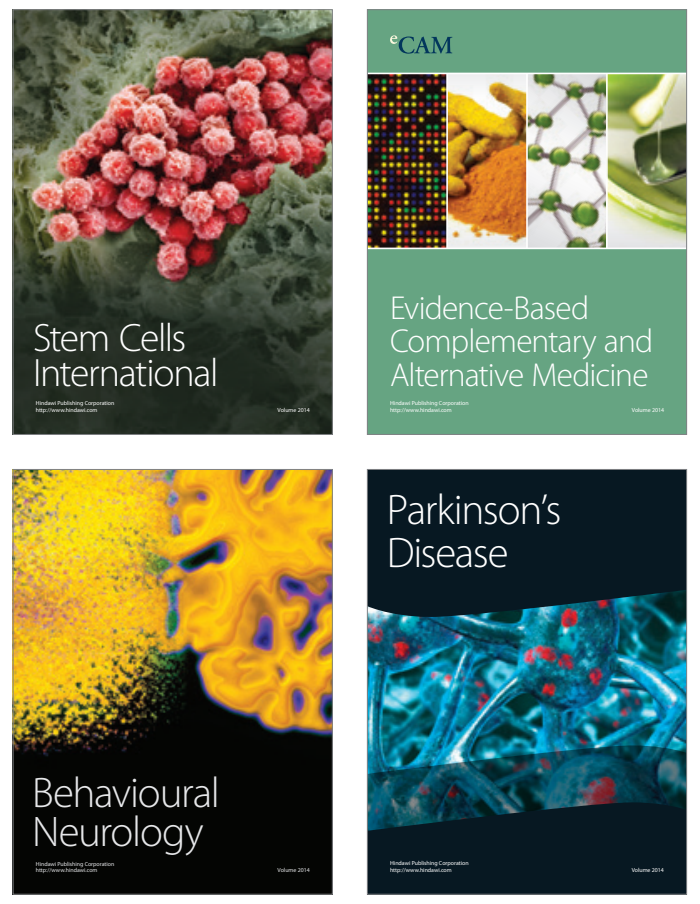
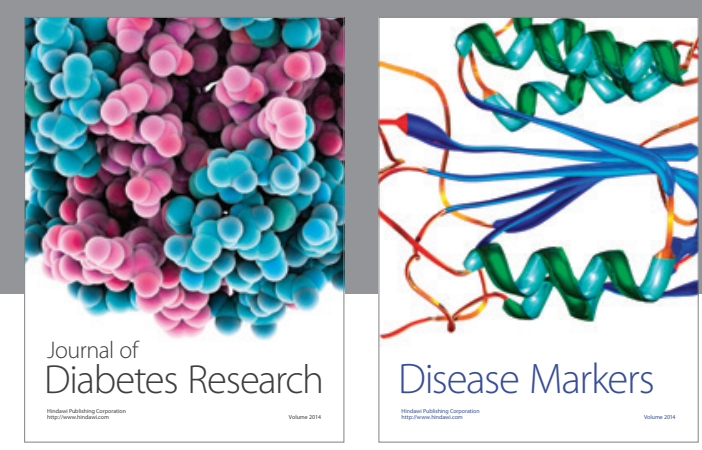

Disease Markers
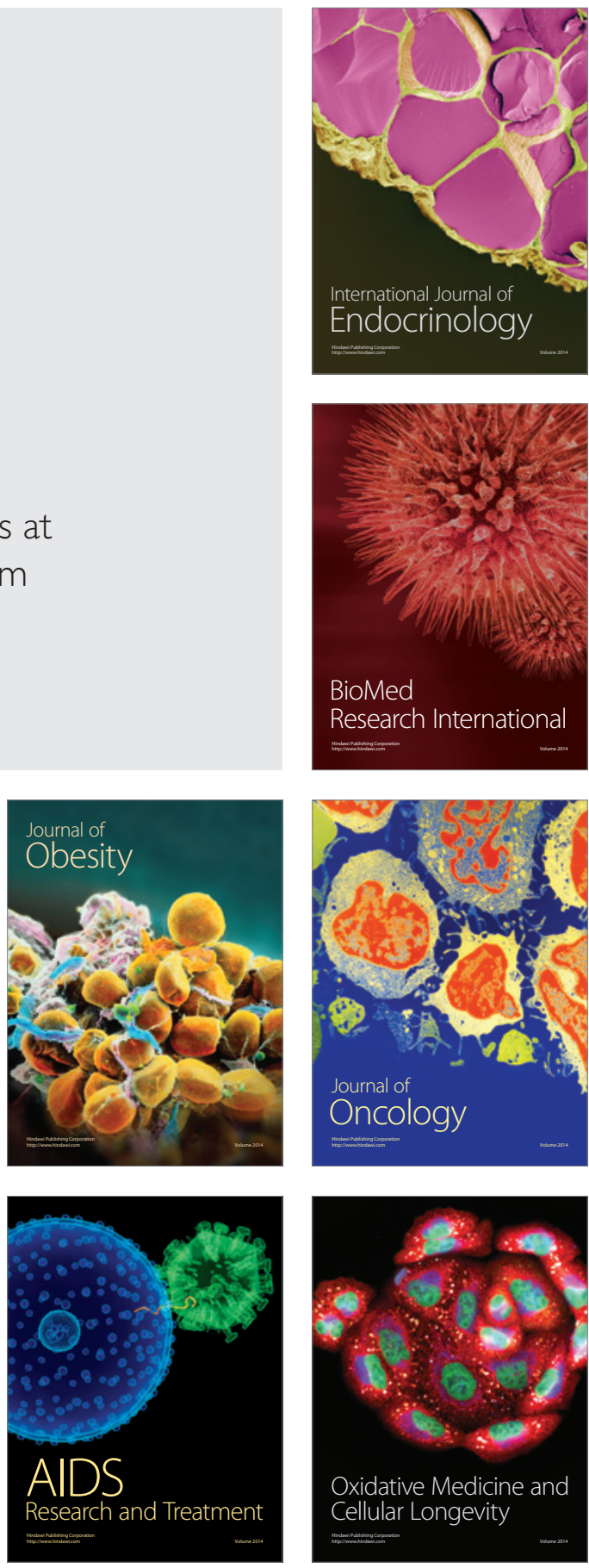